\title{
Brief Cognitive Behavior Therapy for College Students with Depression Symptoms: A Case Study
}

\author{
Linda Setiawati ${ }^{\mathrm{a}}$ and Lifina Dewi Pohan ${ }^{\mathrm{b} *}$ \\ ${ }^{a}$ Clinical Adult Magister-Profession, Faculty of Psychology, Universitas Indonesia, Depok, \\ Indonesia; ${ }^{b}$ Clinical Psychology Department, Faculty of Psychology, Universitas Indonesia, \\ Depok, Indonesia
}

*Corresponding author:

Lifina Dewi Pohan

Clinical Psychology Department

Faculty of Psychology, Universitas Indonesia

Jl. Lkr. Kampus Raya, Depok, Jawa Barat

Indonesia, 16424

Tel.: +62 217270004

E-mail address: lifina.dewi@ui.ac.id 


\title{
Brief Cognitive Behavior Therapy for College Students with Depression Symptoms: A Case Study
}

\begin{abstract}
University life can be perceived as challenging by many students. When students are unable to cope with challenges, it is very likely that they will experience stress. Unresolved stress conditions can impact college students' physical and psychological condition and affect their academic performance. In addition to stress, other psychological effects can arise if college students constantly perceive challenges as negative and unmanageable, especially if they experience a sense of helplessness and/or depression. Psychological interventions can be done to manage students' psychological problems while improving students' well-being and academic success. This study conducted brief cognitive-behavioral therapy (CBT) to treat a 21 year-old college student who experienced depression symptoms. This intervention was chosen because the subject's negative thoughts were identified in conjunction with the depression symptoms. Because the subject also displayed a high level of motivation to overcome the problem, the brief CBT was expected to be effective. The intervention provided consisted of four sessions: one pre-assessment and three intervention sessions, and each session lasted around 120 minutes. After completing the intervention, the subject appeared to feel more capable of recognizing her negative thoughts and then changing them using more positive thoughts. At the beginning of the session, the subject looked depressed, but by the end, seemed more cheerful and exhibited lots of smiles. These research results were obtained from evaluating the subject's depression symptoms qualitatively and showing that brief CBT intervention can overcome a participant's depression symptoms and negative thoughts.
\end{abstract}

Keywords: brief CBT; CBT; college student; depression symptoms

\section{Introduction}

Most college students perceive university life as challenging. The existing research data indicates an increase in the stress levels experienced by college students. Sax (Brougham, Zail, Mendoza, \& Miller, 2009) found that the number of college students who feel overwhelmed increased by around 11\% from 1985 to 2002. The results from the Pierceall and Keim study (2007) on 212 college students in one area of the United States showed that $75 \%$ of participants experienced a moderate level of stress; $12 \%$ experienced a high level of stress; and $13 \%$ experienced a low level of stress. The American College Health Association (ACHA) also found similar results (Mahmoud, Staten, Hall, \& Lennie, 2012), showing that the number of depressed students increased from $10 \%$ in 2000 to $15 \%$ in 2006.

The stressful conditions college students experience can be caused by numerous factors. The age of undergraduate students usually falls into the range of emerging adulthood. This age is typically a transition phase from adolescence to adulthood, so when this occurs in addition to college stress, students' vulnerability to experiencing more stress increases (Towbes and Cohen, cited in Brougham et al., 2009). Furthermore, Brougham, Zail, Mendoza, and Miller (2009) stated that college students entering the young adulthood phase experience role adjustment. Ross, Niebling, and Heckert (1999) stated that college students, especially freshmen, face a variety of 
adaptations for the first time, including staying away from home for the first time, maintaining academic performance, and adapting to a new social environment.

When college students are unable to navigate the challenges or conditions during university life successfully, it is very likely that they will experience stress. Lazarus and Folkman (1984) defined psychological stress as a relationship between the person and the environment where the environment's demands exceed the person's available resources and endanger his or her wellbeing. Struthers, Perry, and Menec (2000) explain that when college students constantly perceived challenges as negative and unmanageable, it leads to gradually developing feelings of helplessness, depression, and stress that all relate to mental health issues.

College students' mental health problems have become a worldwide concern (Bayram \& Bilgel, 2008). The American Psychological Association (APA) (Kitzrow, 2003) states that mental health problems at the individual level can affect all aspects of how college students function, including physical, emotional, cognitive, and interpersonal functions. Bayram and Bilgel (2008) found depression in $27 \%$ of their respondents, which indicates that many college students experience depression during their university life. Individuals reported common symptoms of depression, including disturbed mood, fatigue, low energy levels, sleep and eating problems, concentration impairment, memory problems, decision-making difficulties, loss of motivation and self-esteem, loss of interest in normal activities, social withdrawal, and in some cases, even suicidal thoughts (APA, as cited in Kitzrow, 2003). Hysenbegasi, Hass, and Rowland (2005) also insist that depression is significantly associated with lower performance levels; specifically a decrease in college students' GPAs. Depression experienced by college students can also disrupt their future careers (Hysenbegasi, Hass, \& Rowland, 2005). Therefore, college students who are suffering from depression are expected to get proper and immediate treatment.

Depression is one of the mood disorders based on the classification by the Diagnostic and Statistical Manual of Mental Disorders, 4th edition with revision (DSM-IV-TR). According to Kring, Johnson, Davison, and Neale (2012), the key features of depression are profound feelings of sadness and/or the inability to experience pleasure. The associated observed physical symptoms include fatigue, low energy levels, and physical aches and pains. Individuals with depression also often feel exhausted, but have trouble falling asleep, and/or they struggle with waking up frequently. There are also students who react by sleeping throughout the day. Another common symptom is social withdrawal; when feelings of sadness and helplessness dominate, suicidal thoughts become common.

There are a substantial number of factors that can lead to depression. Kring et al. (2012) describes several causes of depression, one of which is neurobiological factors. Neurobiological factors include genetic factors and play the role of neurotransmitter, which may increase the risk of experiencing depression. Moreover, social and psychological factors also play a role in depressive disorders. Social factors that can cause depression include stressful life events and interpersonal difficulties; while psychological factors include personality and cognitive factors. Several psychological factors that can contribute to or cause depression include neuroticism, Beck's theory about the negative cognitive triad, hopelessness theory, and rumination theory (Kring, Johnson, Davison, \& Neale, 2012). 
Various intervention techniques have been attempted in the effort to overcome depression. Study conducted by Reynolds and Coats (1986) tested the effectiveness of Cognitive-Behavioral Therapy (CBT) and relaxation training to reduce depression levels in teenagers. The results of their study revealed the effectiveness of both treatment options as well as the positive short-term impact on teenagers with depression. There have been other studies using CBT to treat depression in various sample groups, such as the study conducted by Lewinsohn, Clarke, Hops, and Andrews (1990) in adolescents groups; research by Vostanis, Feehan, Grattan, and Bickerton (1996) in children and adolescents; and research by Clarke et al. (2005) on depressed adolescents who received antidepressant drugs. In addition, Church, Asis, and Brooks (2012) utilized the Emotional Freedom Techniques (EFT) for depressed college students. The results of that study indicate that EFT is also an effective method of treating depression. Some of these studies also attempted to use their respective interventions to treat depressive disorders in addition to studies targeting individuals with depression symptoms. A study by Lewinsohn et al. (1990) used DSMIII as the inclusion criterion to screen depressed adolescents, while a study by Church et al. (2012) used scores from the Beck Depression Inventory to classify participants with depression symptoms.

Numerous intervention methods are available that can help overcome depression; CBT is one of the most widely used techniques. Aaron Beck's popular and widely used theory explains that depression is associated with having a negative view of oneself, the world (the situation in hand), and the future. Depressed patients usually display illogical thought patterns that often lead to negative thoughts (Beck \& Alford, 2009). Based on this theory, people with depression acquired negative schema through unpleasant experiences during childhood. These schemas are different from their conscious thoughts and are activated whenever the person faces a similar situation to the one that originally caused the schema to form. People with depression are likely to be overly sensitive to negative feedback. They tend to focus on the negative side of themselves, and they find it difficult to accept any positive feedback they receive. This is due to the development of cognitive biases caused by negative schemas (Kendall \& Ingram, as cited in Kring et al., 2012). In general, people with depression often perform cognitive errors that lead to inaccurate conclusions because of the negative schemas, and usually this creates a vicious cycle.

The substantial number of sessions that are usually performed during a typical CBT has contributed to the development of new CBT approaches that are more efficient and cost-effective for individuals in need. One of the new approaches is the brief CBT (Hazlett-Stevens \& Craske, 2002). Hazlett-Stevens and Craske (2002) found that by reducing the number of treatment sessions, they could also increase efficiency, making the treatment more affordable. In addition, patients' motivation increased because they realized rapid treatment gains. In the current standard, CBT treatment usually takes between 10-20 sessions, while the brief CBT usually takes less than 10 sessions, although there is no defined limitation. The brief CBT approach can also be used in consideration of several conditions, such as clearly defined targets of change, clients' willingness to engage actively during treatment, and the therapist's ability to keep the client continually focused on the specific goals and tasks of treatment (Hazlett-Stevens \& Craske, 2002). Hazlett-Stevens and Craske (2002) looked at the specific applications of the brief CBT and found that it could be used to treat several disorders, including panic disorder, agoraphobia and other phobias, anxiety disorders, depression, and eating disorders. It could also be used in couple's therapy, or to treat alcohol abuse, or pain management. 
This study explains the procedure of a brief CBT used to treat depression symptoms in college students. The study is based on a single case because the subject became available through a university counseling center that provided individual counseling services to every student seeking assistance. The researcher then attempted to make an intervention based on the results of the problem assessment. Subsequently, an intervention was designed based on the brief CBT approach, focusing on negative thoughts.

\section{Methods}

\section{Participant}

\section{Case introduction}

"Lani" was a 21-year-old college student when she came to the counseling center to get help. She is the second child of four children; she has one older sister and two younger brothers. Currently she lives alone in Depok because her family is from Klaten, Central Java.

\section{Presenting complaints}

Lani came to the counseling center to seek for help with initial complaints that she felt like a failure. She expressed that she had felt the same as a child, as a younger sister, and as an older sister. This feeling began to emerge during the second semester of her undergraduate study, when she failed to join the organization in which she was interested. This feeling of failure annoyed Lani more in the middle of her 2015 term breaks. The negative thoughts of feeling she was a failure continued to intensify until Lani felt that she was no longer able to control them. As a result, she was unable to implement many of her plans and the results of the work she did complete were not optimal. These conditions in turn exacerbated the feelings of failure and negative thoughts she already had.

\section{History}

Lani had always experienced good academic achievements since childhood. She ranked high in class, joined many competitions, and managed to win several of them. Lani learned from her sister, who had also achieved good grades since childhood. She was encouraged to follow in her older sister's footsteps to try and get good achievements as well.

During high school, Lani experienced several failures. First, Lani's achievement dropped dramatically in an early semester because of her family's economic problems. This financial problem was serious enough to cause several changes in Lani's life. This problem also caused Lani to prefer being alone, so she began to avoid her friends. Fortunately, Lani was able to improve her grades until her high school graduation. Lani was also not accepted at the organization she wanted, but she managed to join others instead, and her work was considered pretty good. Lani was also not accepted at one of the universities she had applied for, even though she was well prepared for the entrance exam. Ultimately, she was accepted to the same university and the same department as her sister. She also managed to get a scholarship, which helped reduce her parents' financial burden.

\footnotetext{
${ }^{1}$ Participant's real name is not used to maintain confidentiality.
} 
In her early days of college, Lani felt very excited. Her older sister had been an active student with good academic achievements during her time in college, and her example encouraged Lani to be able to achieve similar results. One of the things on her wish list for college was to become a member of an organization of her interest. Unfortunately, Lani was not accepted. She was disappointed and this experience was quite traumatic for her. She had thought she was better than other friends who were accepted, but in the end she was still rejected.

The rejection had a negative impact on her performance in other areas. She had joined university-level organizations but her achievement level was poor. She was so busy with the organization that her Grade Point Average (GPA) decreased. Lani felt quite stressed in her current situations, so thought about leaving the organization, but ultimately she stayed and eventually survived. Lani felt that her negative thoughts hindered her efforts to do well, causing her work to become less optimal and eventually unsatisfactory. Lani tended not to repeat plans she had made since previous results were less satisfactory and made her feel like a failure. This feeling of failure in turn made Lani not dare to carry out further plans, and then this pattern would re-occur. One of these plans Lani had made and was not pursuing as planned was her plan to apply for an internship.

In addition, Lani felt that her achievements thus far did not make her parents feel proud of her. Lani experienced her parents telling other people more about her sister's achievements than her own. When Lani was still in school, she felt that her parents gave her enough attention, but now she felt that her parents treated her differently from her sister and brothers. This was a major disappointment for Lani, because she had always hoped that she could make her parents be proud of her and her achievements.

Lani's feeling of failure first arose when she failed to be accepted as a member in the organization of her interest at the beginning of her college experience. This feeling of failure continued to grow stronger. Moreover, when she was alone and reflecting on her achievements, Lani felt even more disappointed. Many things did not align with her expectations and she felt sure that she had not been able to give her best effort. Lani felt that she could no longer manage her negative thoughts and that this condition was harming her daily life. Lani even tried to share her problems with her friend in hopes of improving, but that did not work either. Eventually, Lani decided to seek help from the student counseling center.

\section{Assessment results}

At each session, Lani looked neat and dressed casually; she also always used lipstick. However, Lani looked sad and gloomy at the beginning of the session. She spoke with a medium volume and a slow tempo to her voice. Her articulation was very clear even though her tone of voice was low. Lani displayed good intellectual capacity by showing that she understood all the questions asked by the researcher, and she was able to contribute her own insight. In general, Lani showed a friendly, relatively open, and cooperative attitude toward the researcher. Multiple diagnoses for Lani are can be seen in Table 1. 
Table 1

Multiaxial diagnosis for Lani

\begin{tabular}{lll}
\hline Axis I & 309.0 & Adjustment Disorder with Depressed Mood \\
Axis II & V71.09 & No Diagnosis \\
Axis III & V71.09 & No Diagnosis \\
Axis IV & & Problems with primary support group (distant relationship in family) \\
& & Problems related to the social environment (difficulty in relationships with college friends) \\
& Occupational problems (unsatisfactory work results) \\
Axis V & GAF $=60$ (on admission) \\
& GAF $=70$ (at discharge) \\
\hline
\end{tabular}

Note. Diagnosis based on Diagnostic and Statistical Manual of Mental Disorders; $4^{\text {th }}$ ed., text rev.; DSM-IV-TR. Adapted from Diagnostic and Statistical Manual of Mental Disorders: DSM-IV-TR, by American Psychiatric Association, 2000, Washington, DC: American Psychiatric Association.

\section{Case conceptualization}

Lani's case conceptualization will use the techniques from Westbrook, Kennerley, and Kirk (2011) to outline an overview of the current problems, a description of the causes and how the problems developed, and an analysis of the maintenance process that made the problems persist. In Lani's case, her negative thoughts became a problem caused by the presence of her negative core belief; that is "I am not worthy." This negative core belief then became the root cause of her depression symptoms. In addition, the negative cycle was reinforced because Lani's reduction in activity. Her problems persisted in a vicious cycle. The details of Lani's case conceptualization can be seen in Figure 1.

\section{Research Design}

The design of this study is a case study in which the number of participants equaled one person $(\mathrm{N}=1)$. By using this research design, the researcher obtained a detailed picture of the participant. This research design also allowed the researcher to provide an intervention for the participant (Gravetter \& Forzano, 2012). The researcher was also able to study the changes experienced by participant before and after the intervention.

\section{Procedure}

The participant in this study was a college student with a typically busy schedule. In addition to busy lecture schedules, college students often participate in many other activities, such as joining organizations, committees, and other voluntary off-campus activities. This situation contributed to the difficulty of finding enough free time to participate in a longer or more therapy sessions; therefore the researcher provided brief therapy for the college student. Moreover, the researcher used a CBT approach with the participant based on the participant's negative core belief having been successfully identified. The participant experienced depression symptoms that were fed by the negative core belief. In selecting this intervention, the researcher also considered the fact that the participant's motivation to change was fairly high. Also, the participant seemed to have a good intellectual capacity based on the initial interview and observation. The participant received a brief Cognitive-Behavioral Therapy (CBT) intervention that was conducted in four sessions over a 7-day period. The results were then qualitatively analyzed by comparing depression symptoms reported by the participant before and after the intervention. 


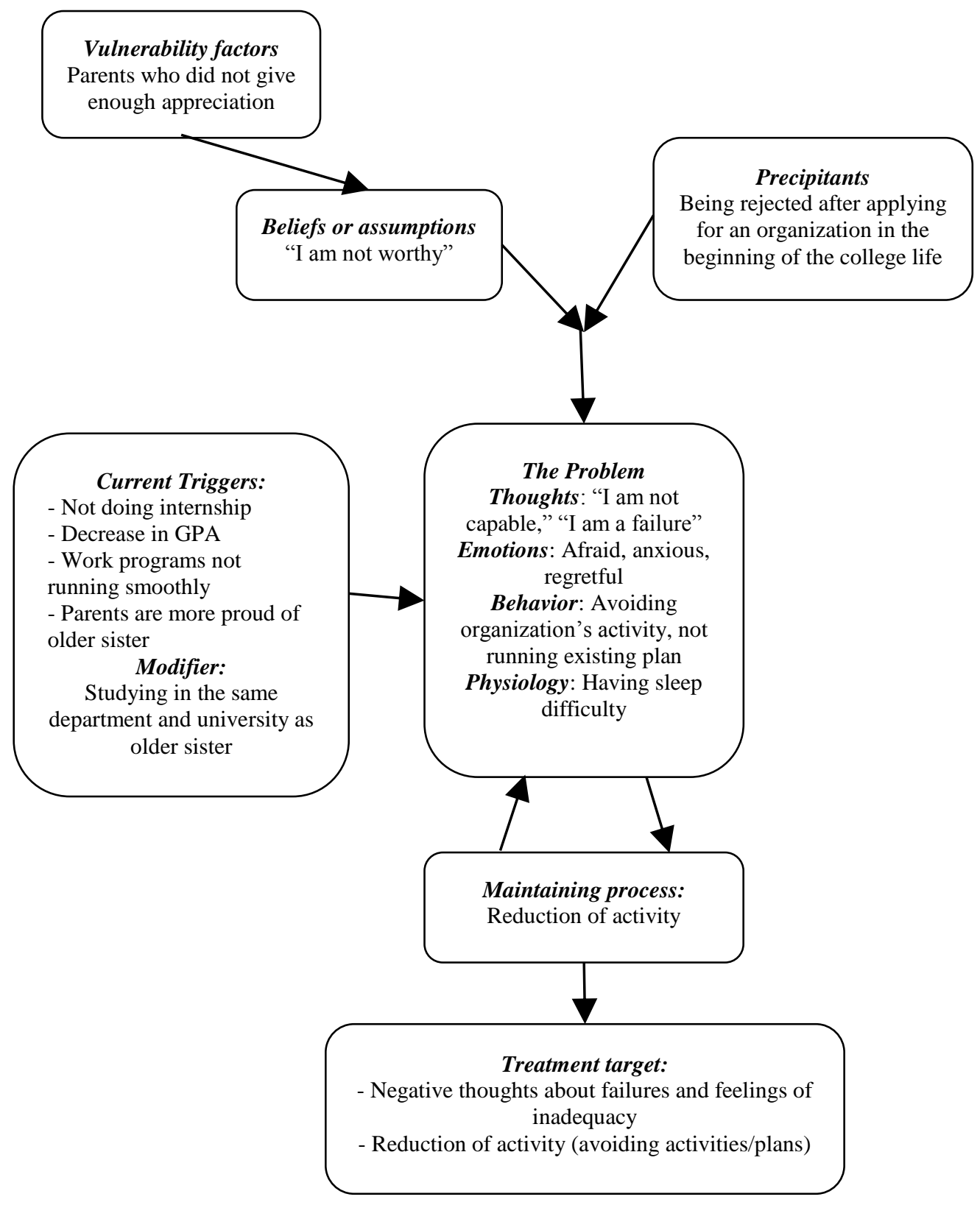

Figure 1. Lani's current problems and several factors related to the problem using CBT assessment and formulation methods. Adapted from An introduction to cognitive behavior therapy: Skills and application ( $2^{\text {nd }}$ ed.) (p. 13), by D. Westbrook, H. Kennerley, and J. Kirk, 2011, London: SAGE Publications

The intervention consisted of several parts, starting with a pre-assessment phase, followed by three sessions of brief CBT intervention, and ending with the termination phase at the last session. 


\section{Pre-assessment}

The researcher conducted the pre-assessment phase at the beginning of the first meeting with the participant. The researcher then conducted an interview to find out about what problems the participant was facing, the participant's current condition, and the participant's background and experiences from her earlier life. The data collection in this phase used interview and observation methods.

\section{Brief CBT}

The intervention given to the participant refers to the intervention module designed by Reynolds and Coats (1986), who conducted CBT interventions to overcome depression in adolescents. Depressed adolescents in this study were selected by using the Beck Depression Inventory score. This module was created by emphasizing self-control exercises for the participants. The referenced module consisted of 8 sessions within 5 weeks, while the intervention in this study consisted of 4 sessions within 7 days. Several sessions with related agenda in the referenced module were merged into one session in this study. The intervention module in this research was also made using several techniques in the CBT intervention approach by Westbrook, Kenerley, and Kirk (2011). Some activities were given to the participant, including self-monitoring (daily thought record), self-identification/self-evaluation (emotional and cognitive aspects), and shortterm/long-term planning. A more detailed description of the module can be seen in Table 2 .

\section{Table 2}

\begin{tabular}{ll} 
Course of Treatment & \multicolumn{1}{c}{ Brief Description } \\
\hline \multicolumn{1}{c}{ Session } & Introduction, initial interview conducted using semi-structured interviewing methods \\
Session 1 & $\begin{array}{l}\text { Improving Lani self-awareness, including her emotions, negative thoughts, and her positive and negative sides. } \\
\text { Giving her home assignments to make daily thought records (self-monitoring about her emotions and following } \\
\text { situation) } \\
\text { Reviewing home assignments, identifying Lani's negative core belief, verbal psychoeducation about the association } \\
\text { between negative core belief, her negative thoughts, and her depression symptoms, also practicing the counter } \\
\text { technique. Giving her home assignments to make daily thoughts records (self-monitoring about her emotions, } \\
\text { following situations, negative thoughts, and counter method) and future plan. } \\
\text { Psychoeducation about maintaining the cycle, psychoeducation about SMART techniques for making future plan, } \\
\text { reviewing all sessions and evaluation, termination }\end{array}$ \\
\hline
\end{tabular}

\section{Termination}

The last phase of the intervention consisted of a termination, which included the researcher's evaluation of the intervention and the participant's evaluation of the changes she experienced during the intervention. In general, the participant showed a positive attitude toward the intervention. After the session ended, the participant expressed that the impact of the intervention was positive; she perceived that she felt more able to control her negative thoughts, she was getting excited to move forward with her plan, and she was smiling more at the last few sessions.

\section{Data Analysis}

This study was conducted with the goal of finding out whether the intervention provided could help to overcome the participant's stated problems. The researcher did not use any quantitative measures to determine the participant's depression level. Therefore, the analysis was done qualitatively by comparing participant's condition before and after the intervention. In particular, her depression symptoms and negative thoughts were compared in the evaluation of her problems. 


\section{Results}

The results showed that Lani experienced a reduction in the depression symptoms over the course of the intervention. The depression symptoms experienced by Lani at the beginning of the session before the intervention were based on DSM-IV-TR for the diagnosis of Major Depressive Disorder (MDD). These were: (1) the emergence of a depressive mood, (2) feelings of failure and worthlessness, (3) sleeping problems, and (4) the emergence of avoidance behavior around certain activities. After the intervention, several changes occurred for each of the depression symptoms, ultimately increasing her GAF score by the end of the session. The explanation of the changes is as follows:

1. Lani no longer showed a depressive mood as at the beginning of the session. The researcher's observations showed that Lani gloominess at the beginning of the session was replaced by lots of smiles at the end of the session, indicating a positive effect.

2. Lani's feelings of failure and worthlessness based on her lack of accomplishment were replaced by more confidence. Lani realized that she also had other prestigious achievements, which increased her self-esteem and her knowledge that she was indeed capable.

3. After the intervention, Lani said that her sleeping problems improved as compared to before she came to see the researcher.

4. Lani's avoidance behavior slowly changed as she began to reconstruct her short-term and long-term planning, using a reward and punishment technique to evaluate the implementation of the plan.

In addition to the improvements in the depression symptoms described above, Lani also experienced changes in her negative thought patterns. At the first meeting, Lani stated that she felt her negative thoughts had interfered with her activities and that she had difficulty controlling those thoughts. The results of the intervention showed that Lani felt that she had gained more control over her negative thoughts by using counter techniques to instill more positive thoughts in her mind.

\section{Discussion}

The results of this study indicate that intervention using a brief CBT approach helped reduce and overcome some depression symptoms in the college student who participated in this study. This is evident based on Lani's confirmation that she did not feel depression symptoms, and that some of the symptoms decreased in intensity after the intervention. The reduction and decrease in Lani's depression symptoms possibly occurred because Lani has a high motivation to change and is actively involved in the changes. Lani was always a strong participant in many activities; she always did all of her homework assignments and was able to learn from her activities and homework assignments.

This study shows that the intervention given could have a positive effect on the participant. On the other hand, this research was not spared from limitations. Limitations in this study include the time constraints that made the intervention time very short, as well as the time gap between sessions. The short time forced sessions to be very full and did not allow much repetition for practicing newly learned materials or skills. The short time gap between sessions may also have had the effect of not giving the participant enough time to process the material received in the previous session before having to move on. This could increase the likelihood that the positive results obtained by participants might not persist over the long term. Future research is expected 
to conduct a follow-up session to check whether the outcome of the intervention is experiencing a short-term or long-term effect.

Another limitation in this study is the lack of quantitative or self-reporting measures to assess the depression level experienced by the participant. Data analysis in this study was done qualitatively by comparing the participant's depression symptoms before and after the intervention. The first author who conducted the intervention made the comparison. The absence of quantitative data made it difficult to ensure that the participant really improved in terms of her depression level; this also made it difficult to draw the conclusion that brief CBT is an effective treatment to overcome depression. The result of this study indicated that brief CBT is effective in treating the participant's depression, but it cannot be generalized to other people who are depressed.

Nevertheless, the results of this study could still be useful for future research that addresses related topics; namely, that cognitive-behavioral approaches could be beneficial in overcoming depression symptoms caused by negative thoughts. The therapy provided over a brief period is also able to cause significant changes if the participants have a high motivation to change and are willing to be actively involved in the therapy. If neither of these conditions is present, giving a brief intervention might not be possible and it might not result in positive outcomes for the participants. Good intellectual capacity of participants also facilitates the course of the intervention process; therefore, this intervention type might be a good option for college students, who are considered to have inherent good intellectual capacity.

In the future, cognitive-behavior therapy could be one of the treatment options used to overcome many problems caused by an individual's negative thoughts, such as low self-esteem problems or phobias. By addressing negative thoughts, the symptoms or problems that arise from them could also be resolved. Researchers could also use brief therapy more frequently to help overcome participants' problems because this type of therapy has the potential to make participants feel the positive impact of therapy within a short time. This condition is in accordance with the characteristics of Indonesian clients who expect instant results during therapy so that they will feel more motivated to seek help from professionals such as psychologists.

\section{References}

American Psychiatric Association. (2000). Diagnostic and statistical manual of mental disorders: DSM-IV-TR. Washington, DC: American Psychiatric Association.

Bayram, N., \& Bilgel, N. (2008). The prevalence and socio-demographic correlations of depression, anxiety and stress among a group of university students. Social Psychiatry and Psychiatric Epidemiology, 43 (8), 667-672. DOI: 10.1007/s00127008-0345-x

Beck, A. T., \& Alford, B. A. (2009). Depression: Causes and treatment (2 ${ }^{\text {nd }}$ ed.). Pennsylvania: University of Pennsylvania Press.

Brougham, R. R., Zail, C. M., Mendoza, C. M., Miller, J. R. (2009). Stress, sex differences, and coping strategies among college students. Current Psychology, 28 (2), 85-97. DOI: 10.1007/s12144-009-9047-0

Church, D., De Asis, M. A., \& Brooks, A. J. (2012). Brief group intervention using emotional freedom techniques for depression in college students: A randomized controlled trial. Depression Research and Treatment, 12, 1-7. DOI: $10.1155 / 2012 / 257172$

Clarke, G., Debar, L., Lynch, F., Powell, J., Gale, J., O’Connor, E., Ludman, E., Bush, T., Lin, E. H. B., Von Korff, M. \& Hertert, S. (2005). A randomized effectiveness trial of brief cognitive-behavioral therapy for depressed adolescents receiving antidepressant medication. Journal of the American Academy of Child and Adolescent Psychiatry, 44 (9), 888-898. DOI: 10.1097/01.chi.0000171904.23947.54 
Gravetter, F. J., \& Forzano, L. B. (2012). Research methods for the behavioural sciences. Belmont, CA: Wadsworth Cengage Learning.

Hazlett-Stevens, H., \& Craske, M. G. (2002). Brief cognitive-behavioral therapy: Definition and scientific foundations. In F. W. Bond \& W. Dryden (Eds.), Handbook of brief cognitive behaviour therapy (pp. 1-20). West Sussex: John Wiley \& Sons.

Hysenbegasi, A., Hass, S. L., \& Rowland. C. R. (2005). The impact of depression on the academic productivity of university students. The Journal of Mental Health Policy and Economics, 8 (3), 145-151.

Kitzrow, M. A. (2003). The mental health needs of today's college students: Challenges and recommendations. NASPA Journal, 41 (1), 167-181. DOI: 10.2202/1949-6605.1310

Kring, A. M., Johnson, S. L., Davison, G., \& Neale, J. (2012). Abnormal psychology (12 ${ }^{\text {th }}$ ed.). Hoboken, NJ: John Wiley \& Sons.

Lazarus, R. S., \& Folkman, S. (1984). Stress, appraisal, and coping. New York: Springer Publishing Company.

Lewinsohn, P. M., Clarke, G. N., Hops, H., \& Andrews, J. (1990). Cognitive-behavioral treatment for depressed adolescents. Behavior Therapy, 21, 385-401. DOI: 10.1016/s0005-7894(05)80353-3

Mahmoud, J. S. R., State, R. T., Hall, L. A., \& Lennie, T. A. (2012). The relationship among yound adult college students' depression, anxiety, stress, demographics, life satisfaction, and coping styles. Issues in Mental Health Nursing, 33, 149156. DOI: $10.3109 / 01612840.2011 .632708$

Pierceall, E. A., \& Keim, M. C. (2007). Stress and coping strategies among community college studens. Community College Journal of Research and Practice, 31 (9), 703-712. DOI: 10.1007/s12144-009-9047-0

Reynolds, W. M., \& Coats, K. I. (1986). A comparison of cognitive-behavioral therapy and relaxation training for the treatment of depression in adolescents. Journal of Consulting and Clinical Psychology, 54 (5), 653-660. DOI: 10.1037/0022006x.54.5.653

Ross, S. E., Niebling, B. C., \& Heckert, T. M. (1999). Sources of stress among college students. College Student Journal, 33 (2), 312-317.

Struthers, C. W., Perry, R. P., Menec, V. H. (2000). An examination of the relationship among academic stress, coping, motivation, and performance in college. Research in Higher Education, 41 (5), 581-592. DOI: 10.1023/a:1007094931292

Vostanis, P., Feehan, C., Grattan, E., \& Bickerton, W. (1996). A randomised controlled out-patient trial of cognitive-behavioral treatment for children and adolescents with depression: 9-month follow-up. Journal of Affective Disorders, 40, 105116.

Westbrook, D., Kennerley, H., \& Kirk, J. (2011). An introduction to cognitive behavior therapy: Skills and applications (2 ${ }^{\text {nd }}$ ed.). London: SAGE Publications. 